\title{
Whither Family Medicine? Our Past, Future, and Enduring Scope of Practice
}

David Loxterkamp, MD

\begin{abstract}
After 3 decades in private practice, I joined the faculty of a nearby residency program. Like most family medicine residencies, it follows a curriculum that my physician father would have recognized: heavy emphasis on inpatient medicine; short shrift to continuity care. Despite a changing marketplace, there is still a disconnect between how we train graduates (for full spectrum care) and where they end up (in ambulatory practices). Is our identity disappearing? I contend that the primary and indispensable duty of a residency program is to model professional values and prepare residents to live and work in sustainable communities. Though the scope of practice will vary, family physicians still pride themselves in putting the needs of their patients at its center.
\end{abstract}

(Fam Med. 2019;51(7):555-8.)

doi: 10.22454/FamMed.2019.633317

To write prescriptions is easy, but to come to an understanding with people is hard.

-Franz Kafka, The Country Doctor

\section{The Patient}

What is the future of family medicine? The question is an enduring one, and perhaps it is unanswerable. Or, rather, it must be answered by each generation in its turn. As our specialty crests its 50 th year, we seem unsettled by the loss of ownership and control in the workplace, the unrelenting distraction of electronic documentation, the expanding license and multidisciplinary makeup of the health care team, and the profusion of retail clinics and urgent care centers in our own backyard. We have boxed ourselves into tight quarters-the clinic, emergency department, and hospital—and talk to each another less and less.
These are not insurmountable challenges; they are merely ours to meet.

We might begin by asking "what do our patients need?" A 2005 British survey ${ }^{1}$ found that most respondents wanted to know that health care would be there when they needed it. They wanted their doctor to take their views and preferences seriously; they wanted to learn how to help themselves and have access to reliable information and treatment options. And they did not want to worry about how they would pay for their health care.

American surveys have provided similar results. ${ }^{2-6}$ But where are the surveys of those who don't think of themselves as consumers, and those who don't consider that they might have a choice or deserve an opinion? Family practice waiting rooms are filled with the friendless, the helpless, and the voiceless. What would they say they that wanted or needed? If asked, would they even reply?

A representative sample straggles into our recovery group meeting every Thursday afternoon. Today Britni arrives 15 minutes late. Again. Disrupting our mindful meditation exercise and testing the strict rule on punctuality. The paper bag under her arm is stuffed with soda and snacks that constitute her daily diet. She jiggles a leg, munches on chips, and retreats into her own universe, barely acknowledging those around her. In her distractions, she becomes one.

Afterward, during our medication renewal visit, I ask her how she is feeling. Depressed, she tells me. Her back molars are disintegrating and she is in constant pain. "I don't want to be another 25 year-old toothless wonder." We both know that Medicaid will pay for extractions, but not restoration or dentures.

She is depressed, too, about her living situation - a rat infested trailer with a leaky roof, costly electric heat, and a boyfriend who lost his license and, consequently, his minimum-wage job. They got by last winter on Medicaid, child support from an ex-boyfriend, and fuel assistance from a local church. Then she lost Medicaid. Our care manager helped her get it back, along with Temporary Assistance for Needy Families

\footnotetext{
From Northern Light Eastern Maine Medical Center Family Medicine Residency Program, Bangor, ME.
} 
(TANF) and food stamps, but she is still worried: her boyfriend's unemployment benefits run out in a month.

She spends her days watching videos and caring for the newborn. Her oldest child lives mostly with her ex-boyfriend; consequently, he threatens to cut off child support. I have noticed how every positive comment, every positive development in her life involves her children. "Oh, by the way," she tells me, "I'm pregnant again."

Through it all, Britni has been taking her medication as prescribed. She is attending group. Her urine tests are consistently positive for buprenorphine and only rarely for marijuana. I remind her that she is a good mother; that she has the grit and determination to make a better life for herself and her children; that she has come too far in her recovery to turn back. Mostly, I listen. And identify with her struggle and pain. I begin to see the outlines of what might help her, beyond the methylphenidate or escitalopram she received in the past. As Franz Kafka wrote, "To write prescriptions is easy. To come to an understanding with people is hard." Better to offer her, as an alternative, the vision of the person she wants to be. And as we speak, she seems more my neighbor, my daughter, my friend.

There can be no efficiency in treating patients like Britni. How do you quantify a life lost to drugs, or in this case, the several lives of her children? The accountants can only tabulate the number of encounters linked to her ID. The revenue, in other words, that could be generated by up-coding the visit or adding a procedure. Or allowing the doctor to spend just enough time to issue a prescription.

Yesterday was my last day in group. As I explained, it was time for me to leave the practice and spend my last working years as a teacher of family medicine. I assured everyone that I loved them and was proud of them-words that, undoubtedly, many had never heard. I asked them to imagine a future self who, years later when we crossed paths, would proudly tell me what had become of their lives. Britni literally bounced out of her chair. She would be living in a real house with all her children. She would have a real job that would pay for store-bought clothes. And she would still be sober.

I am not sanguine about her dreams coming true. That she has hopes and expectations at all is miracle enough, and that she is moving toward them, albeit on a bumpy and uneven climb. When I met with Britni after group to write her prescription, she brought along the baby-daddy. Danny wanted to thank me for all that I had done for their family, their future. He gave me an awkward hug, as unexpected and gratifying as any gift I have ever received. This why I am a family doctor.

\section{The Program}

The future of family medicine is on display in its residency programs. Here, a substantial part of the curriculum is still taught in the hospital and under the tutelage of specialists, just as when I was a resident. What has changed is the way doctors communicate. Patients are now described in terms of risk scores and screening results. Diagnoses are made by checklist rather than gestalt. The repository of meaning lies within the electronic health record, where the story of illness is shrink-wrapped or omitted altogether. Once true only in the teaching hospital, family practice centers are now run by protocol, workflow, divisions of labor, and interdisciplinary teams. Graduates will sit for a high-stakes certification exam, and many choose a fourth year of training, interview for a windowless job in a hospital network, and embark on the long road of student loan repayment. Few are sanguine about their career prospects. Fewer still plan to enter what was once the norm: fullscope family medicine.

Nevertheless, residents become very accomplished "jacks of all trades," holding their own in the intensive care unit, delivery suite, and emergency department. Their degree of dedication, idealism, and compassion are above reproach. They are as smart and prepared for practice as any class that came before them. But have they learned what it means to be a family doctor?

This is something that a faculty cannot profess, and fellowships are not designed to provide. There is no recertification module for professionalism. Another year of training is hard to square with the obvious competencies of those who need less: nurse practitioners, physician assistants, and our Canadian counterparts." How do we become family doctors, anyway? Through countless patient encounters, in a process that continues long after the residency ends. Here, we find lessons of lasting value: the importance of listening to patients before we lecture them. The indispensability of courage as we speak up for those who cannot. Humility as the best means to master our mistakes. The enormous return on investment that follows every generous, selfless, and faithful act. The healing that occurs when patients are restored to their self-identified community. It is from a sense of belonging that humans derive their sense of purpose and meaning, identity, and self-worth, and the strength to overcome adversity. For the family doctor, connection is our currency.

How can we nurture these values during residency? The answer lies in professional identity formation, ${ }^{7}$ borrowing from tradition, relying on reflective writing, small group discussion, journaling, a reading of the history and literature of medicine, personal essay writing and other forms of self-expression, community service, faculty role-modeling, and mentoring (Table 1). This cannot happen in a vacuum. It requires a tangible example of community life within our training programs, and sustaining this may be our biggest challenge of all. 
I grew up in a small farming community in northwest Iowa. Most of my friends were sons of farmers whose dedication to the land and its produce, to sustainability and stewardship, was inherited, like the land itself, from the previous generation. Each farmer managed his own operation, but also participated in a local cooperative that dried and stored the harvest for bulk sale when market conditions improved. Since everyone on the farm made a proportional contribution to its success, I saw little of my friends during planting and harvest seasons. Crops were rotated; every fourth year, fields were left fallow. Wide fence rows and timber were home to pheasant, grouse, rabbit, and deer. Farmers shopped, schooled, and worshipped locally, and their surplus beef and garden vegetables were, in turn, purchased by the townspeople.

Farms have since quadrupled in size, and their dwindling numbers no longer support a local high school or much more than a convenience store in town. Yet the family farm still serves as an able example of responsible ecology. Under the shadow of the sponsoring institution, residency programs and their training practices have an obligation to preserve their distinct culture. To do so, they must have control over their budgets, hiring practices, curriculum development, program mission, and social identity. They might then invest in the neighborhood, offer extended hours and enhanced services, and stay small enough to preserve a sense of intimacy and trust between patients and staff. And amid the chaos and cacophony of a training practice, they must insist upon slack time ${ }^{8}$ in order to promote selfreflection, casual conversation, and staff collaboration (Table 2).

It is still our job to help residents pass their certifying exams and become proficient in office and bedside procedures. It is equally our duty to prepare them for a future as yet unimagined, and provide them with the skill and agency to align our health care system with the needs of

Table 1: Values of a Family Physician

- Listening as a means to understanding

- Honesty as a means to trust

- Humility as a means to wisdom

- Courage as a means to advocacy

- Generosity and shared self-sacrifice as means to loyalty

- Empathic imagination as a means to community

- Connection as a means to healing and health

Table 2: Assets of a Robust Family Medicine Residency Program

\begin{tabular}{|l|l|}
\hline \multicolumn{1}{|c|}{ Asset } & \multicolumn{1}{c|}{ Examples } \\
\hline Local control & $\begin{array}{l}\text { Discretion over the budget | control of the } \\
\text { curriculum }\end{array}$ \\
\hline Sense of time and place & Right size | extended hours | necessary services \\
\hline Office interdependency & $\begin{array}{l}\text { Cross-training | integrated teams | inclusive } \\
\text { meetings }\end{array}$ \\
\hline Community engagement & Leadership | service | local residence \\
\hline $\begin{array}{l}\text { Maintenance of the } \\
\text { margins }\end{array}$ & Slack | self-reflection | essential conversations \\
\hline
\end{tabular}

patients. Doctors are clinicians first, but they need to know why some systems work and others fail; and they need to unravel the riddle of a Kafka tale, wherein a country doctor rides through a midnight blizzard in order to attend a small child with an axe wound. The doctor discovers that he cannot save the boy, and realizes that the journey will cost him both his servant girl and his reputation. "The parson sits at home and unravels his vestments," he laments, "but the doctor is supposed to be omnipotent with his merciful surgeon's hand. Well, as it pleases them... if they misuse me for sacred ends, I let that happen to me, too."

\section{The Promise}

Whither family medicine? The old center of full-spectrum care no longer holds. New realities confront and energize our graduates, and employers hire them for niche roles. Thus they flock to two dozen different fellowships in more than 400 locations advertised on the American Academy of Family Physicians website. Yet we cannot let residency training become just the last hurdle before fellowship. If the goal becomes merely one of producing doctors with marketable techniques and a tidy set of answers, we have failed society and its greater hopes for us.

I believe that family doctors will always be generalist-trained, relationship-centered, and communityoriented. We are generalists not by virtue of what we do or know, but in the way we ask questions and construct solutions in response to the suffering of those who sit before us. We trust the looping arc of conversation, one that leads to a deeper understanding and sense of belonging. We know the value of patience, reassurance, and gentle guidance, of talk when impatient action would soothe only the doctor's insecurities.

More than anything else, we are a profession of values, which is why we can claim to be a profession at all. Our job is to uphold them in every relationship, recognizing their importance for health and healing. Our promise lies in preserving a healing culture within our own practices, and between the ambulatory doctor and his hospital counterpart. Whither family medicine? Toward connection. Toward belonging. The relationships we build begin with our own.

Let's reevaluate the old formulas. Let's not let the market dictate our legacy. For family medicine is still a time-honored calling. We must strive 
to preserve and transmit its values so that the needs of patients-whatever they may be-determine the full scope of our practice.

\section{Footnote:}

* I realize this is a qualified claim, and one easily dismissed. My argument is that it takes months to become a sufficient practitioner, and a career to become a proficient one.

CORRESPONDENCE: Address correspondence to Dr David Loxterkamp, Northern Light Eastern Maine Medical Center Family Medicine Residency Program, 895 Union Street, Suite 12, Bangor, ME 04401-3054. 207-973-7979. david.loxterkamp@gmail.com.

\section{References}

1. Coulter A. What do patients and the public want from primary care? BMJ. 2005;331(7526):1199-1201.

2. Cheraghi-Sohi S, Hole AR, Mead N, et al. What patients want from primary care consultations: a discrete choice experiment to identify patients' priorities. Ann Fam Med. 2008;6(2):107115.

3. Detsky AS. What patients really want from health care. JAMA. 2011;306(22):2500-2501.

4. Bensing J, Rimondini M, Visser A. What patients want. Patient Educ Couns. 2013;90(3):287-290.

5. Anderson R, Barbara A, Feldman S. What patients want: a content analysis of key qualities that influence patient satisfaction. Medical Practice Management. 2007;March/April: 25561
6. Lopez A, Detz A, Ratanawongsa N, Sarkar U. What patients say about their doctors online. J Gen Intern Med. 2012;7(6):685-92.

7. Wald HS. Professional identity (trans)formation in medical education: reflection, relationship, resilience. Acad Med. 2015;90(6):701-706.

8. Mullainathan S, Shafir E. Scarcity: Why Having Too Little Means So Much. New York: Henry Holt and Company; 2013

9. Kafka F. Selected Short Stories of Franz Kafka. New York: Random House; 1952 